Article

\title{
Optimization of Inspection Period in Natural Stone Claddings
}

\author{
Cláudia Ferreira ${ }^{1, *(\mathbb{D}}$, Ana Silva ${ }^{1}\left(\mathbb{D}\right.$, Jorge de Brito ${ }^{1,2} \mathbb{D}^{\mathbb{D}}$, Ilídio S. Dias ${ }^{1}$ and \\ Inês Flores-Colen 1,2 (D)
}

1 CERIS, Instituto Superior Técnico, Universidade de Lisboa, Av. Rovisco Pais, 1049-001 Lisbon, Portugal; anasilva931@msn.com (A.S.); jb@civil.ist.utl.pt (J.d.B.); ilidio.dias@tecnico.ulisboa.pt (I.S.D.); ines.flores.colen@tecnico.ulisboa.pt (I.F.-C.)

2 Department of Civil Engineering, Architecture and Georesources, Instituto Superior Técnico, Universidade de Lisboa, Av. Rovisco Pais, 1049-001 Lisbon, Portugal

* Correspondence: claudiaarferreira@tecnico.ulisboa.pt

Received: 30 October 2020; Accepted: 18 November 2020; Published: 20 November 2020

check for updates

\begin{abstract}
In condition-based maintenance plans, the schedule of inspections is an important step. Condition-based actions are performed according to prescribed condition criteria (i.e., condition, cost, availability, among other factors), and the main purpose of inspections is to evaluate the façade's condition and plan its correction in order to reduce the risk of failure of the cladding. Therefore, the main goal of this study is to implement multi-objective optimization to understand whether there is an optimal time interval for performing the inspections. For that purpose, a Petri-net condition maintenance model is used to assess the influence of different maintenance plans on the overall degradation of natural stone claddings. In this model, the maintenance activities can only be performed after an inspection has been carried out. The definition of the best maintenance policy results in a conflict of objectives. Owners/managers seek to achieve a maintenance strategy that minimizes service life costs and maintain the cladding in a safe and minimal degradation condition. Multi-objective optimization procedures are capable of considering several conflicting objectives. In this paper, the objective functions considered are minimization of the service life costs, maximization of the efficiency index, maximization of the service life, and minimization of the total number of replacements over the time horizon.
\end{abstract}

Keywords: inspections; multi-objective optimization; natural stone claddings; degradation; maintenance

\section{Introduction}

As the first line of defense against the environmental agents, the claddings are the most susceptible element to degradation [1]. However, for many years, little or no attention has been paid to their maintenance [2] since building owners/managers assumed that this element plays a more decorative than structural role [3]. As a result, severe degradation of the building façades has become a serious problem, both economic and cultural, in several countries [4,5].

However, over the last years, this belief has been changed, and stakeholders start to understand that appropriate and continuous maintenance is the most economical way to ensure the long-term durability of assets and improve the quality and aesthetic perception of the cities without compromising the assets' reliability or safety [6,7]. Consequently, nowadays, decision-makers on service life management of the built environment are confronted by high demands of deteriorated assets and lower financial and human resources [8].

In the scope of the service life management of the built environment, significant work still needs to be done since consolidated guidelines are still not available [9]. For example, regular inspections to 
assess the condition and to define maintenance activities, in general, are not mandatory or regulated [10], depending mainly on the country [11,12] and the type of element to be assessed [13], and the definition of the end of the service life is subjective, depending on the owners'/users' demands, aesthetic appearance, and budgets [14]. Nevertheless, a significant amount of effort has been undertaken to understand the natural aging phenomena and predict the degradation processes of buildings' façades and claddings $[5,15]$, to define more adequate repair techniques for anomalies' correction and elimination of their causes [16-20], and to develop approaches for establishing optimum management of maintenance strategies [21-24].

For decision-makers, establishing an approach for the definition of optimum maintenance plans is the ultimate goal. However, the definition of an optimum maintenance plan implies a trade-off between distinct parameters. For example, usually, stakeholders pursue maintenance plans that minimize service life costs and maintain the assets in a safe and minimal degradation condition [25]. In this sense, multi-objective optimization procedures can be successfully used to achieve an optimal relationship between the multiple goals associated with service life management [8]. Specifically, these types of procedures can provide multiple trade-off solutions for decision-makers to select a rational alternative by using higher-level information [8].

Since the definition of the best maintenance plan results in a conflict of objectives, in this study, a multi-objective optimization procedure using genetic algorithms (GA), available in software MatLab ${ }^{\circledR}$ [26], is implemented to schedule the optimal time interval between inspections of building claddings. For that purpose, a condition-based maintenance model based on Petri nets is used to analyze the influence that different maintenance plans have on the overall degradation of natural stone claddings (NSC). In this model, the maintenance activities can only be performed after an inspection has been carried out. In condition-based maintenance plans, the maintenance activities are performed according to prescribed condition criteria (i.e., condition, cost, availability, risks, among other factors). Therefore, inspections should precede the decision-making process and are essential to evaluate the cladding's condition and plan their correction. In other words, the information collected during inspection helps to select the best interventions in order to reduce the risk of failure of the cladding. In the multi-objective optimization procedure, the following conflicting objectives are considered: (i) minimization of the service life cycle costs in terms of maintenance; (ii) maximization of the efficiency index of the maintenance plan; (iii) maximization of the service life; (iv) minimization of the total number of replacements over the time horizon.

In the literature, there are several works that deal with optimal maintenance planning. For instance, some studies have focused on the schedule of maintenance activities: in bridges, in highway transportation networks [27-30]; on water distribution systems [31,32]; on power plants [33,34]; on other civil infrastructures [35-37]. Concerning the optimal planning of inspection in civil infrastructures, Berardi et al. [38] implemented a multi-objective genetic algorithm (MOGA) to prioritize inspection works in a large real-life sewer network. A trade-off between the risk of failures and the cost of inspections is used to identify the sewers that should be first inspected. This methodology identifies the set of sewers where the propensity and the consequences of failures are higher. Later, still in a sewer distribution system, Elmasry et al. [39] presented a work where a multi-objective optimization approach was used to optimize inspections in sewer pipelines. In this model, resource allocation is considered by minimizing the time and cost spent on inspections and maximizing the number of pipelines inspected. A more mathematical perspective about the optimization of inspection intervals was given by Zio and Viadana [40]. The authors investigated the use of different evolutionary algorithms (EA) to optimize the inspection intervals of safety systems in nuclear power plants. In this paper, the problem is both treated as single-objective and multi-objective optimization. In the multi-objective optimization approach, the availability of the facility, the cost of the inspection, and the exposure time of the maintenance operators are the different conflicting objective functions. Finally, Kim and Frangopol [8] applied the multi-objective probabilistic optimization process (MOPOP) for optimum inspection and repair scheduling of fatigue-sensitive structures. This methodology considers two alternatives to determine 
the best single optimum inspection plan. In decision-making before MOPOP, the weight factors are used to convert the multiple objectives into a single objective, and, consequently, a single optimum solution for inspection planning is obtained. On the other hand, in decision-making after MOPOP, the essential objectives are identified and used to select the best Pareto optimal solution.

According to the ISO 15686-1 standard [41], maintenance can be defined as the "combination of all technical and associated administrative actions during the service life to retain a building, or its parts, in a state in which it can perform its required functions", where inspection is one of those actions. As can be seen from the studies above, when the aim is to optimize the planning of inspections in civil infrastructures, the literature is scarce and becomes even scarcer when the planning of inspections in building components is considered since, for many years, the maintenance of building components has not been a major concern for stakeholders [42]. However, the results of these studies show that there are advantages in using multi-objective optimization procedures to optimize inspection intervals. It is a flexible and rational approach, and the results are useful for decision-makers since the most effective and efficient sequences of inspections are identified based on the restrictions imposed, allowing achieving significant cost-saving when compared with the current inspection practices. Furthermore, the genetic algorithms are revealed to be accurate for the optimization of inspection periods, helping to plan inspections that monitor the actual behavior of the elements, in particular for those where there is no in-service data. Therefore, the aim of this study is to develop a framework based on multi-objective optimization procedures and to optimize the inspection period in NSC. As a buildings' constructive solution, NSC is widely used; however, little information is available in the literature about the inspection period, and the values available are deterministic and based on the experience of experts. Therefore, one of the hypotheses behind this study is to understand whether there is an optimal time interval for performing the inspections on NSC, whether it is in agreement with the values available in the literature, and whether these values are constant or change according to the owners' requirements and demands.

\section{Materials and Methods}

\subsection{Natural Stone Cladding}

Around the world, the durability, attractiveness, and versatility of natural stone as an external cladding material are highly recognized [1,43]. Furthermore, in several situations, its low maintenance costs clearly justify the high initial production and construction costs [1]. However, in the past years, the increase of environmental pollution along with construction errors and lack of maintenance have contributed to the increase of the built heritage's degradation [44-47]. Consequently, the development of tools to understand the behavior of this cladding material and reduce the risks for society is extremely relevant.

\subsubsection{Classification System}

The degradation condition of the buildings' claddings has been assessed and characterized by different authors $[10,12,48]$. The classification system implemented in this study (Table 1) was introduced by Silva et al. [49], and it is based on the visual assessment of the extent of the cladding that is affected by the different anomalies considered. Five discrete conditions are adopted in this classification system, varying between condition A (no visible degradation-most favorable condition) and $\mathrm{E}$ (generalized degradation-most unfavorable condition). In Figure 1, some examples of the visual condition of NSC in each degradation level are presented. Condition A (Figure 1a) represents an NSC with no visible degradation; in condition B (Figure 1b), the NSC begins to present some visual anomalies (superficial dirt and stains) and some loss of integrity anomalies (material degradation and cracking), which do not put at risk the NSC's performance; condition C (Figure 1c) corresponds to an NSC with slight degradation, with anomalies related with joints and substrate degradation and loss of integrity, such as open joint, scaling of the edges and fracture; condition D (Figure 1d) corresponds to 
an NSC with moderate degradation, where there is an evolution of the condition C anomalies; finally, in condition $\mathrm{E}$ (none of the case studies within the sample belongs to condition E), the NSC shows a generalized degradation, with severe loss of adherence anomalies. The overall degradation condition of the NSC is quantified through the severity of degradation index, $S_{w}$, which is given by the ratio between the area affected by the defects observed in an NSC, weighted according to their severity, and a reference area equivalent to the total cladding area with the highest possible level of degradation (Equation (1)).

$$
S_{w}=\frac{\sum\left(A_{n} \times k_{n} \times k_{a, n}\right)}{A \times \sum k_{\max }},
$$

where $S_{w}$ is the severity of degradation of the cladding (in \%); $k_{n}$ the multiplying factor of anomaly $n$, as a function of its degradation condition (varying between 0 and 4 ); $k_{a, n}$ a weighting factor corresponding to the relative weight of the anomaly detected $\left(k_{a, n} \mathrm{R}+\right) ; A_{n}$ the area of cladding affected by an anomaly $n\left(\right.$ in $\left.^{2}\right) ; A$ the façade's area (in $\left.\mathrm{m}^{2}\right) ; \sum\left(k_{\max }\right)$ the sum of the multiplying factors for the highest degradation condition of each anomaly type. The type of anomalies, $k_{n}$ and $k_{a, n}$ coefficient's values, and the relationship between the severity of degradation, $S_{w}$, and the degradation condition, $C$, for the NSC are presented in Table 1.

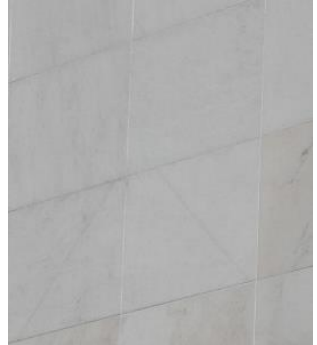

(a)

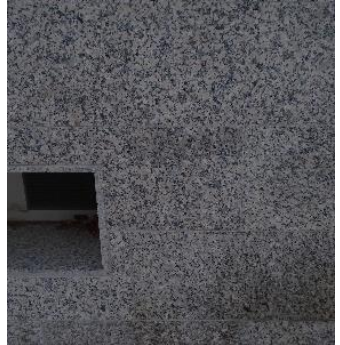

(b)

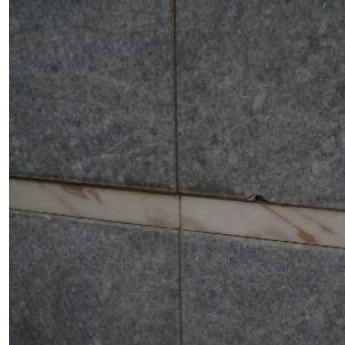

(c)

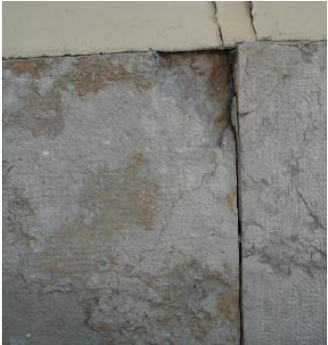

(d)

Figure 1. Illustrative examples of NSC (natural stone claddings) in different degradation conditions. None of the case studies within the sample belongs to condition E: (a) condition A; (b) condition B; (c) condition $\mathrm{C}$; (d) condition D.

\subsubsection{Inspection Period}

Regarding the adequate inspection period in NSC, the information in the literature is limited. Although not directly applied to claddings, Branco and de Brito [50] pointed out that current inspection should occur at the 15-month interval to detect anomalies of rapid evolution, to monitor anomalies detected in previous inspections, and to check all aspects that are influenced by the seasons and, every 5 years, current inspection should be replaced by detailed inspections in order to determine the extent, severity, and respective causes of the anomalies. Later, in a study about the durability of marble claddings, where the causes and mechanisms for the loss of integrity of these elements are discussed, Grelk et al. [43] referred that the inspections must be carried out at intervals between 2 and 5 years. In Portugal, the RGEU/Decree-Law No. 177/2001 (New Juridical Regime of Urbanization and Edification) [51] suggests that after 8 years, the buildings should be subjected to maintenance actions (without specifying the type of actions that should be carried out). In this sense, since NSC is a durable cladding material, it seems reasonable to consider that periodic inspections should be performed every 8 years, even to evaluate the degradation condition of the buildings and to confirm whether the maintenance actions are really necessary. More recently, Madureira et al. [23] proposed that inspections should be carried out every 5 years and that specialized equipment should be used to detect anomalies related to the presence of water and loss of adhesion. Based on these works, the time interval between inspections varies between 2 and 8 years, 5 -year being the most common value. Furthermore, in the literature, these inspections only serve to assess the degradation condition of the NSC, without any action being carried out to improve the condition of the claddings. 
Table 1. NSC (natural stone claddings) classification system (data adapted from [49]).

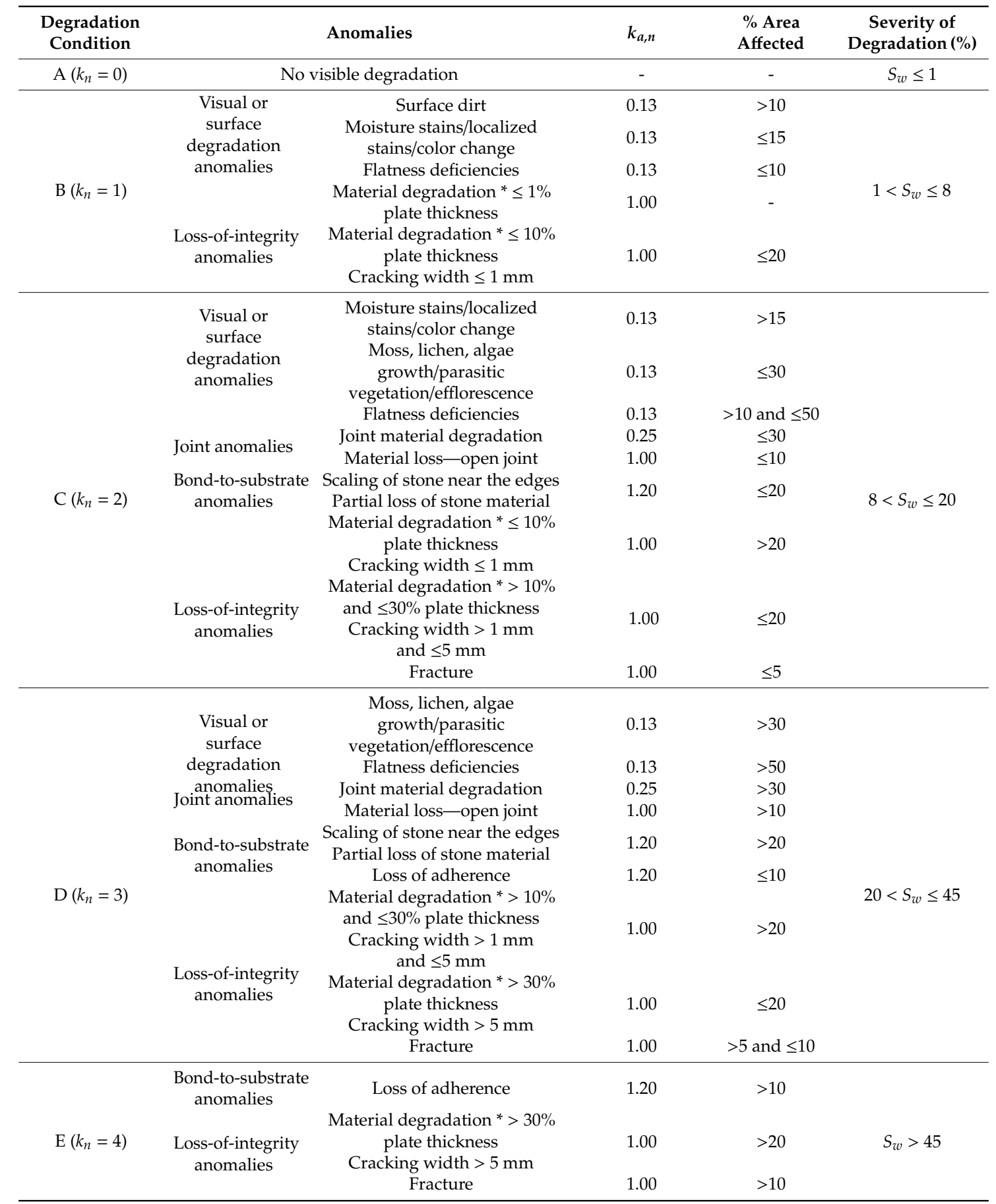

${ }^{*}$ Material degradation is meant to be every anomaly that involves loss of volume of the stone material.

\subsection{Formulation of the Optimization Problem}

Multi-objective optimization problems involve two or more objective functions that are in conflict, meaning that the improvement of one goal implies the sacrifice of another goal [52]. In the same way, as in the single-objective optimization problems, multi-objective optimization problems may contain different constraints that any feasible solution must satisfy, i.e., a multi-objective optimization problem can be expressed as follows [53]: 


$$
\begin{array}{lll}
\text { Minimize/maximize: } & f_{m}(x) & m=1,2, \ldots, M \\
\text { Subject to: } & g_{j}(x) \geq 0 & j=1,2, \ldots, J \\
& h_{k}(x)=0 & k=1,2, \ldots, K \\
& x_{i, L} \leq x_{i} \leq x_{i, U} & i=1,2, \ldots, I
\end{array}
$$

where $f_{m}(x)$ is the objective function, and $g_{j}(x), h_{k}(x), x_{i, L}, x_{i, U}$ the constraints.

However, in multi-objective optimization problems, the concept of an optimal solution is replaced by the concept of non-dominated solutions. By definition, a feasible solution $x^{(1)}$ dominates the feasible solution $x^{(2)}$ if both the following conditions are true [53]:

1. The solution $x^{(1)}$ is no worse than $x^{(2)}$ in any objective;

2. The solution $x^{(1)}$ is strictly better than $x^{(2)}$ in at least one objective.

All solutions that are not dominated by any other solution of the set are called a non-dominated solution. In Figure 2, an example of a multi-objective optimization problem is shown. From the set of six solutions shown in Figure 2, the solutions linked by the dashed line are non-dominated solutions. The improvement in one objective, $f_{1}$, requires a sacrifice in the other objective, $f_{2}$. These solutions arrange a non-dominated front when viewed together on the objective space [53].

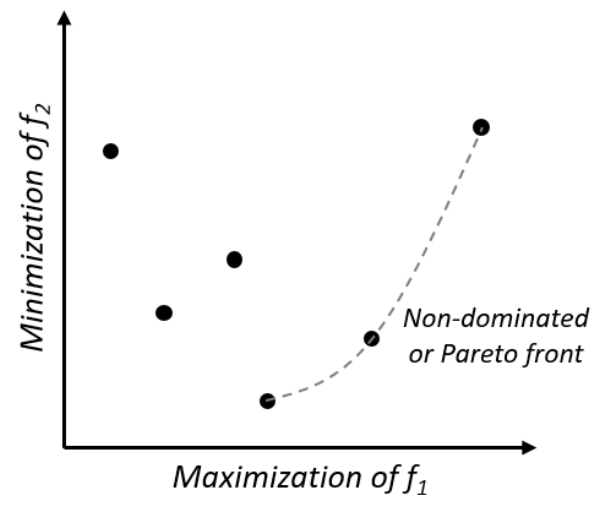

Figure 2. Example of the non-dominated front of a multi-objective optimization problem.

In this study, the optimization problem considers four objectives. The multi-objective algorithm is used to optimize the time interval between inspections. Therefore, in this optimization problem, the time interval between inspections is considered the design variable, while the objective functions are the: (i) minimization of the maintenance costs; (ii) maximization of the service life; (iii) maximization of the efficiency index; (iv) minimization of the number of replacements. The design variable is subjected to a constraint, i.e., the (optimal) time interval between inspections should vary between a maximum and a minimum value.

The analytical formulation of this optimization problem is given by:

Find: $\quad$ The (optimal) time interval between inspections, $t_{\text {insp }}$

So that: Minimization of the maintenance costs

Maximization of the efficiency index

Maximization of the service life

Subject to: $t_{\text {insp, } \min } \geq t_{\text {insp }} \geq t_{\text {insp, } \max }$

The main interactions among the different models of the optimization procedure are presented in Figure 3. In this procedure, the optimization model is the most important characteristic. Herein, multi-objective genetic algorithms are employed. One distinctive feature of the GA is the use of a population of solutions, allowing searching within several Pareto optimal solutions simultaneously [53]. 
Furthermore, the GA does not need any further information about continuity or differentiability [40]. The management of cladding degradation, maintenance interventions, and maintenance costs are governed by the maintenance model.

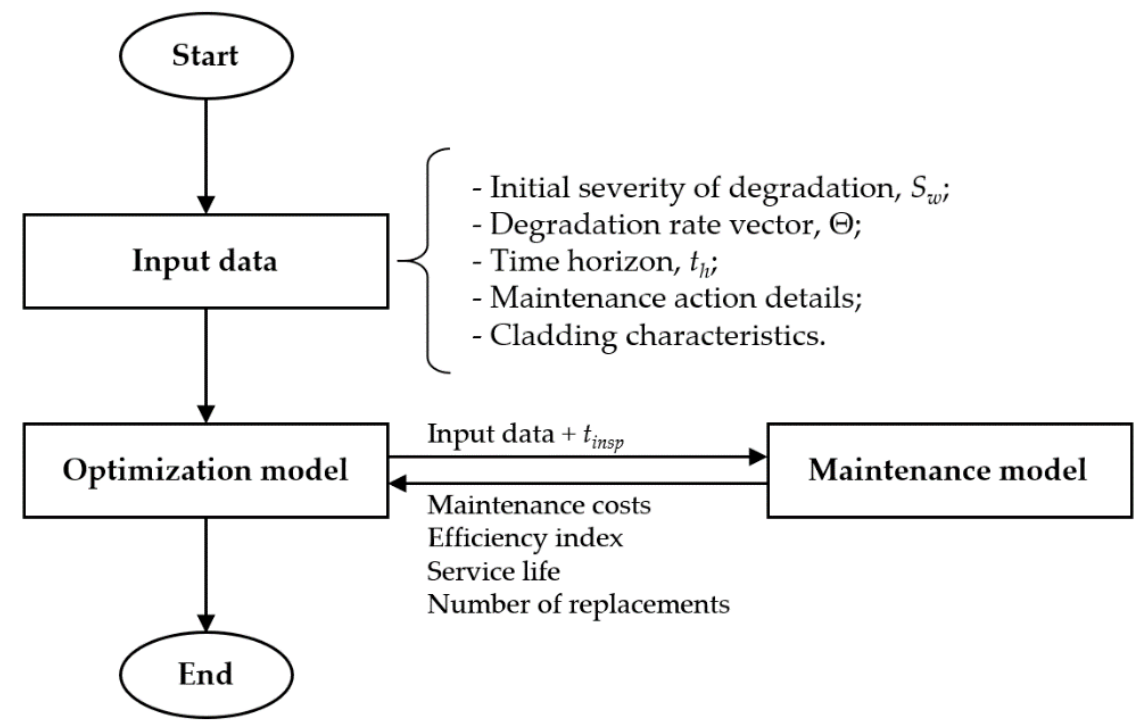

Figure 3. Flowchart of the main interactions within the different models of the multi-objective optimization problem.

The initial severity of degradation of the cladding, $S_{w}$; the degradation rate vector, $\Theta$; the time horizon of the analysis, $t_{h}$; the maintenance action details; the cladding characteristics are the input data of the optimization procedure. The optimization procedure begins by setting a value for the design variable (time interval between inspections, $t_{\text {insp }}$ ). In the maintenance model, considering the input data and the time interval between inspections set, the degradation and cumulative maintenance cost profiles are computed. An extensive description of the procedure followed in the maintenance model can be found in Ferreira et al. [54]. In the oncoming step, the objective functions (the maintenance cost of the maintenance strategy, the efficiency index, the service life, and the number of total replacements performed during the time horizon) are computed. This procedure is iteratively repeated until the predefined stopping criteria in the GA are satisfied (the algorithm stops if the average relative change in the best fitness function value over 100 generations is less than or equal to $10^{-4}$ [26]). In the following sections, the theoretical background of the objective functions is provided.

\subsubsection{Maintenance Costs}

The maintenance cost is computed by Equation (4) and corresponds to the expected life-cycle cost, $L C C$, of the maintenance strategy under analysis during the time horizon, $t_{h}$. Specifically, this value corresponds to the total costs that the stakeholder will incur during the time horizon to keep the cladding in operation [55]. In this methodology, the construction costs are neglected.

$$
L C C=\sum C_{\text {inspection }, t}+\sum C_{\text {maintenance, },},
$$

where $\sum C_{\text {inspection, }}$ refers to the accumulated costs associated with inspection over the time horizon, $\sum C_{\text {maintenance, } t}$ the accumulated costs associated with other maintenance activities, and $t$ the year of the intervention's occurrence. To consider the future investments, Equations (5) and (6) are used to compute the net present value of the inspection and maintenance activities, respectively [56].

$$
\sum C_{\text {inspection }, t}=\frac{\sum C_{\text {inspection }}}{(1+v)^{t}}
$$




$$
\sum C_{\text {maintenance, }}=\frac{\sum C_{\text {maintenance }}}{(1+v)^{t}},
$$

where $C_{\text {inspection }}$ and $C_{\text {maintenance }}$ are the inspection and maintenance costs at time $t$, respectively, and $v$ the real discount rate. In this methodology, a real discount rate of $6 \%$ (private sector environment) $[55,57]$ is adopted.

\subsubsection{Efficiency Index}

The efficiency index, EI, refers to the ability of the maintenance strategy under analysis to keep the cladding in a good performance condition (in terms of degradation). In this methodology, EI can be formulated as [58]:

$$
E I=\frac{\int S_{w} d t}{100 \cdot t_{h}}
$$

where $\int S_{w}(t) d t$ is the area underneath the degradation profile (which represents the loss of performance of the cladding over time), and $100 \cdot t_{h}$ is the area underneath the degradation profile when there is no degradation (utopian situation). This parameter varies between 0 (when the severity of degradation is always $100 \%$ or condition E) and 1 (when the severity of degradation is always $0 \%$ or condition $\mathrm{A}$ ). The higher the $E I$ value, the more efficient the maintenance strategy is over time.

\subsubsection{Service Life}

The estimation of the service life is based on the cumulative distribution functions (CDF) obtained through the degradation process [58]. Based on previous works [5] and experts' judgment, the expected end of the service life (ESL) of the cladding is reached when the degradation condition D is achieved. Numerically, ESL is defined by a probability of transition between degradation conditions C and D equal to $50 \%$.

\subsubsection{Number of Replacements}

Finally, the number of replacements represents the average number of times that the cladding is fully refurbished (that is, the cladding reaches the end of the service life) during the time horizon in the maintenance strategy under analysis.

\section{Results}

In this study, natural stone claddings are analyzed as a case study. To analyze the influence of the different maintenance plans, three maintenance strategies (MS) are considered: MS1—total replacement only; MS2-a combination of minor interventions and total replacement; MS3 - a combination of cleaning operations, minor interventions, and total replacement. The MS1 represents the maintenance strategy most implemented by the owners/managers [45], while MS3 specifies the most complete maintenance strategy. Furthermore, as input data of the multi-objective optimization problem, a time horizon, $t_{h}$, of 150 years is considered, and the initial severity of degradation, $S_{w}$, of $0 \%$ (condition A) at the beginning of the analysis is adopted. In the maintenance model, it is assumed that the degradation process follows a Weibull distribution, and, in Table 2, the optimal parameters of the degradation process (degradation rate vector, $\Theta$ ) are presented in terms of the mean and standard deviation of the sojourn time in each degradation condition. Specifically, according to a Weibull distribution, for an NSC, a transition between conditions A and B takes, on average, 4.1 years to occur, with a standard deviation of 7.0 years. The same analysis can be used for other condition transitions. The choice of the best probability distribution that describes the degradation process is performed through the maximization of the logarithm of the likelihood [59]. A more detailed explanation of these assumptions is provided in Ferreira et al. [58]. However, in relation to the data shown in Table 2, the high standard deviation of $T_{a}$ is due to the reduced interval associated with the severity of degradation, $S_{w}$, and the anomalies considered to quantify the severity of degradation in conditions A and B. From Table 1, 
the severity of degradation of condition $\mathrm{A}$ varies between 0 and $1 \%$, showing that the deposit of surface dirt is sufficient to change the NSC from condition A to B. Moreover, the classification of an NSC is highly dependent on the inspector, geographic location, exposure conditions, and time of the year. The maintenance action details (costs, application zone conditions, and impacts) are presented in Table 3, and the cladding characteristics are the condition limits given in Table 1 (last column), which relates the two scales of the classification system. The information presented in Table 3 can be read in the following way: a minor intervention in an NSC has a cost of $68.80 € / \mathrm{m}^{2}$, and it is applied when the cladding reaches condition $\mathrm{C}$, and improves the cladding's condition to $\mathrm{B}$, with a probability of $80.4 \%$, or maintains condition $C$, with a probability of $19.6 \%$. More detailed information about the cost calculation can be found in Ferreira et al. [58]. Regarding the design variable constraints (Equation (3)), and based on Section 2.1.2, it is assumed that the (optimal) time interval between inspection varies between 1 and 20 years. The lower limit is defined based on the literature, while the upper limit is increased in relation to the values found in the literature to determine the optimal time interval between inspection for NSC. Finally, it should be mentioned that all the solutions analyzed in this study are technically feasible.

Table 2. Degradation rate vector, $\Theta$.

\begin{tabular}{ccccc}
\hline Parameters & $\boldsymbol{T}_{\boldsymbol{A}}$ & $\boldsymbol{T}_{\boldsymbol{B}}$ & $\boldsymbol{T}_{\boldsymbol{C}}$ & $\boldsymbol{T}_{\boldsymbol{D}}$ \\
\hline Mean (years) & 4.1 & 42.9 & 22.4 & 49.9 \\
Standard deviation (years) & 7.0 & 10.3 & 1.4 & 2.4 \\
\hline$T_{A}$-transition between conditions A and B; & & \\
$T_{B}$-transition between conditions B and C; & & \\
$T_{C}$ 一transition between conditions C and D; & & \\
$T_{D}$-transition between conditions D and E. & \\
\hline
\end{tabular}

Table 3. Maintenance action details.

\begin{tabular}{cccccc}
\hline \multirow{2}{*}{ Maintenance Actions } & \multirow{2}{*}{ Cost $\left(\mathbf{\epsilon} / \mathbf{m}^{\mathbf{2}}\right)$} & \multirow{2}{*}{ Application Zone Conditions } & \multicolumn{3}{c}{ Impact of the Maintenance Actions } \\
\cline { 4 - 6 } & & & $\boldsymbol{P}_{\boldsymbol{A}} \mathbf{( \% )}$ & $\boldsymbol{P}_{\boldsymbol{B}} \mathbf{( \% )}$ & $\boldsymbol{P}_{\boldsymbol{C}}(\mathbf{\%})$ \\
\hline Inspection & 1.03 & All & - & - & - \\
Cleaning operations & 31.37 & $\mathrm{~B}$ & 15.0 & 85.0 & - \\
Minor interventions & 68.80 & $\mathrm{C}$ & 0 & 80.4 & 19.6 \\
Total replacement & 149.51 & $\mathrm{D}, \mathrm{E}$ & 100.0 & - & - \\
\hline
\end{tabular}

$P_{A}$-probability of the application zone changing to condition $\mathrm{A} ;$

$P_{B}$ - probability of the application zone changing to condition $\mathrm{B}$;

$P_{C}$ - probability of the application zone changing to condition $C$.

\subsection{Comparison of the Optimal Solutions for the Different Maintenance Strategies}

In Figures 4 and 5, the Pareto solutions obtained for the three maintenance strategies are compared. In Figure 4, the solutions are displayed through pairs of the four objective functions (maintenance cost, service life, efficiency index, and the number of total replacements), while, in Figure 5, the time interval between inspections (design variable), $t_{\text {insp }}$, is compared with the four objective functions. A total of 18 optimal solutions are obtained for each maintenance strategy.

For each maintenance strategy, three optimal solutions are highlighted in Figures 4 and 5 . The values of the four objective functions and the design variable are presented in Table 4 . The optimal solutions, for MS1, are identified as S1 to S3; for MS2, as S4 to S6; for MS3, as S7 to S9. By comparing the three optimal solutions for MS1, solution S1, which is associated with a higher time interval between inspections, yields a lower maintenance cost, but its performance is also lower. On the other hand, solution S3, which is associated with a lower time interval between inspections, implies higher maintenance costs but ensures a higher performance of the NSC over the time horizon. Lastly, solution S2 represents a trade-off between solutions S1 and S3. A similar consideration can be made for MS2 and MS3. 
Table 4. Comparison of the four objective functions and the design variable of the optimal solutions highlighted.

\begin{tabular}{|c|c|c|c|c|c|c|}
\hline $\begin{array}{c}\text { Maintenance } \\
\text { Strategy }\end{array}$ & $\begin{array}{l}\text { Optimal } \\
\text { Solution }\end{array}$ & $\begin{array}{c}\text { Time } \\
\text { Interval, } \\
t_{\text {insp }} \text { (Years) }\end{array}$ & $\begin{array}{l}\text { Maintenance } \\
\text { Costs }\left(€ / \mathrm{m}^{2}\right)\end{array}$ & $\begin{array}{l}\text { Service Life } \\
\text { (Years) }\end{array}$ & $\begin{array}{l}\text { Efficiency } \\
\text { Index }\end{array}$ & $\begin{array}{l}\text { Number of } \\
\text { Replacements }\end{array}$ \\
\hline \multirow{3}{*}{ MS1 } & S1 & 18.8 & 2.54 & 70 & 0.9057 & 1.17 \\
\hline & S2 & 10.9 & 3.61 & 71 & 0.9155 & 1.42 \\
\hline & S3 & 1.0 & 20.47 & 70 & 0.9316 & 1.75 \\
\hline \multirow{3}{*}{ MS2 } & S4 & 18.8 & 4.32 & 163 & 0.9292 & 0.14 \\
\hline & S5 & 11.9 & 5.82 & 157 & 0.9367 & 0.35 \\
\hline & S6 & 1.0 & 23.91 & 143 & 0.9449 & 0.57 \\
\hline \multirow{3}{*}{ MS3 } & S7 & 19.0 & 14.58 & 270 & 0.9460 & 0.02 \\
\hline & S8 & 15.4 & 18.79 & 245 & 0.9489 & 0.02 \\
\hline & S9 & 1.0 & 74.59 & 154 & 0.9494 & 0.46 \\
\hline
\end{tabular}
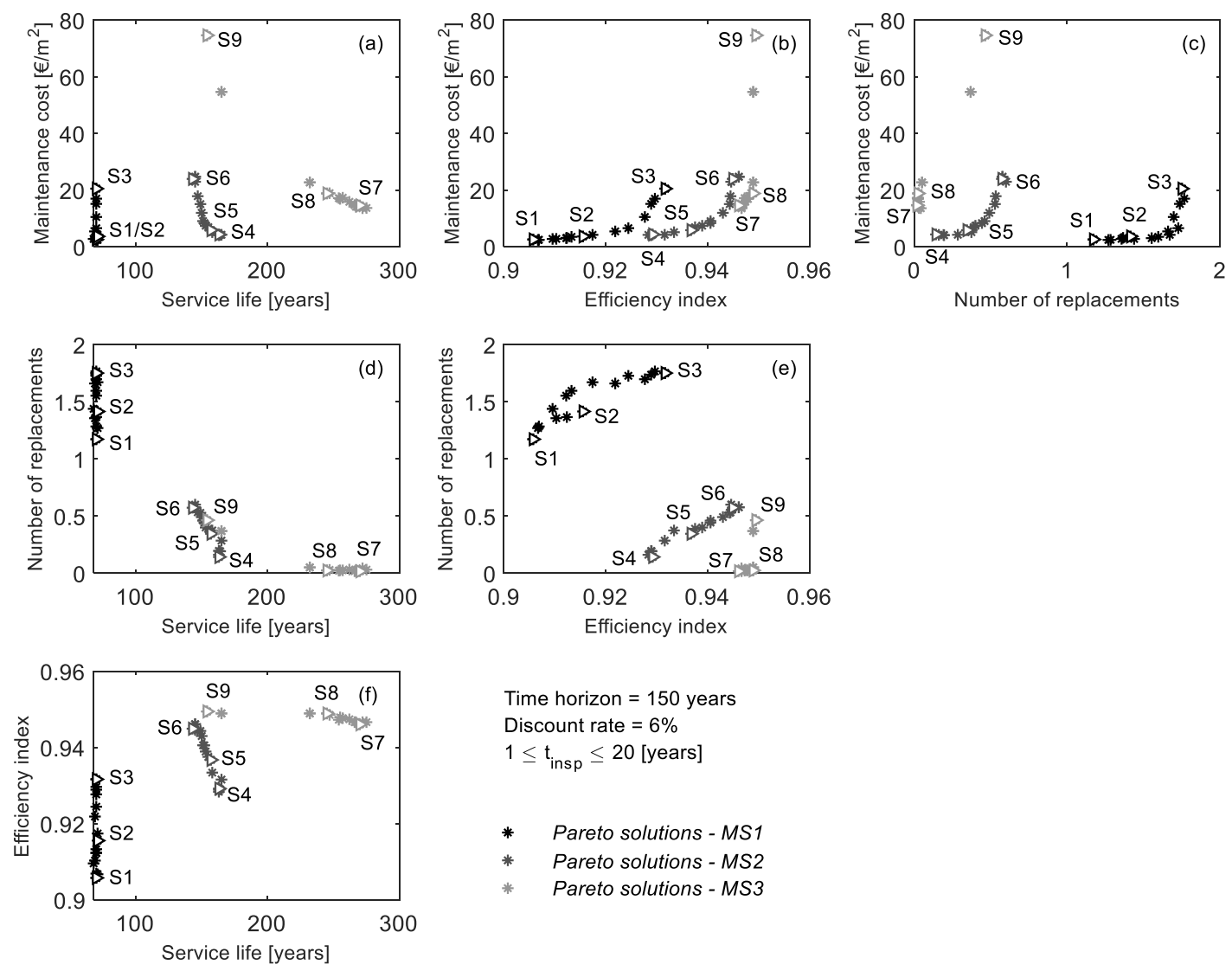

Time horizon $=150$ years

Discount rate $=6 \%$

$1 \leq \mathrm{t}_{\text {insp }} \leq 20$ [years]

* Pareto solutions - MS1

* Pareto solutions - MS2

* Pareto solutions - MS3

Figure 4. Comparison of the Pareto solutions bi-dimensional space: (a) relationship between maintenance cost and service life; (b) relationship between maintenance cost and efficiency index; (c) relationship between maintenance cost and the number of replacements; (d) relationship between the number of replacements and service life; (e) relationship between the number of replacements and efficiency index; (f) relationship between efficiency index and service life. 

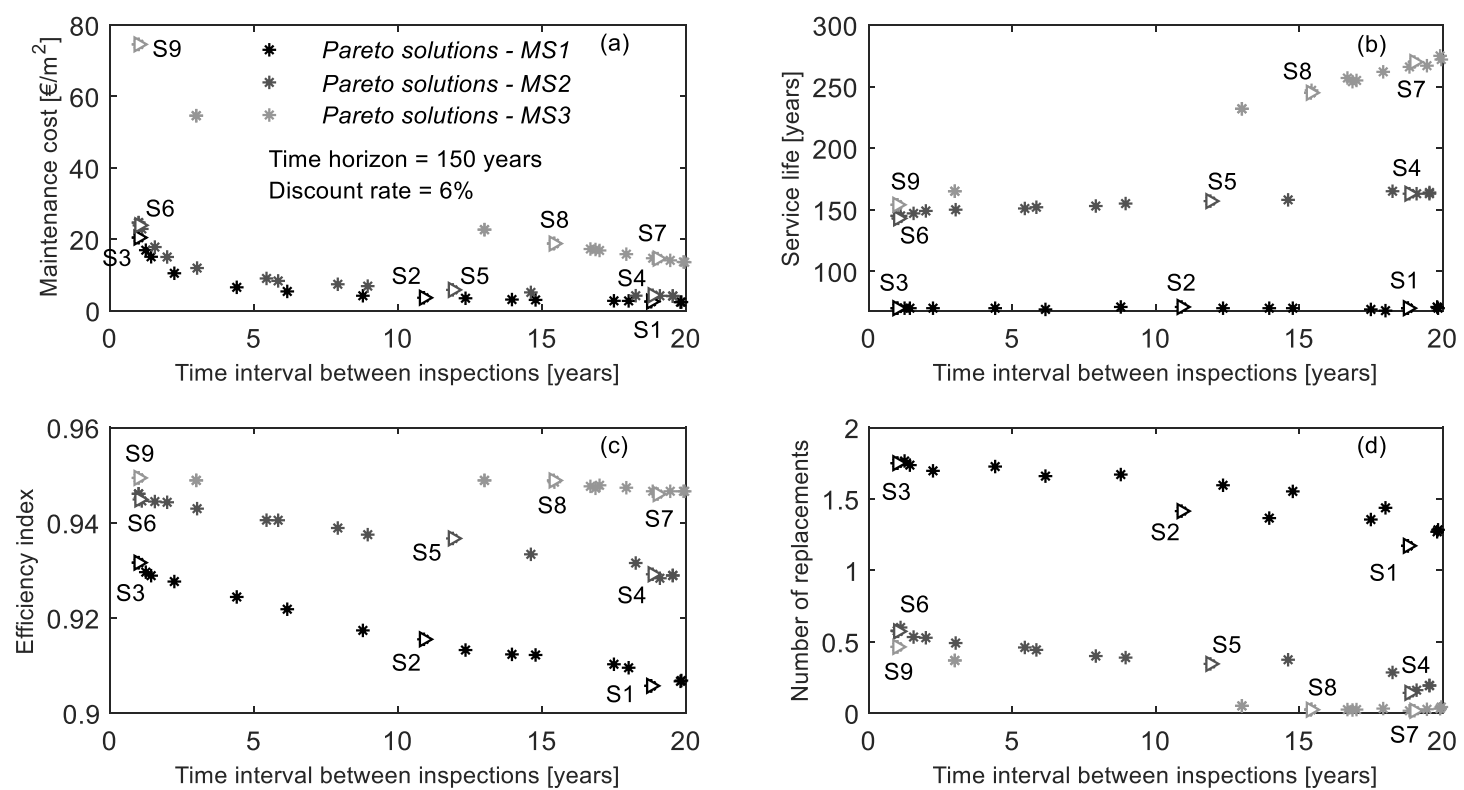

Figure 5. Comparison of the design variable (time interval between inspections, $t_{\text {insp }}$ ) with the four objective functions: (a) relationship between maintenance cost and the time interval between inspections; (b) relationship between service life and the time interval between inspections; (c) relationship between efficiency index and the time interval between inspections; (d) relationship between the number of replacements and time interval between inspections.

In Figure 4, a non-linear relationship between the objective functions is observed. In general, maintenance costs tend to decrease as service life increases (Figure 4a) and increase with the increase in the efficiency index (Figure $4 \mathrm{~b}$ ) and the number of replacements during the time horizon (Figure 4c). On the other hand, the number of replacements tends to decrease as service life increases (Figure 4d) and to increase with the increase in the efficiency index (Figure 4e), and, finally, the efficiency index tends to decrease as service life increases (Figure 4f). Figure 5 reveals that the maintenance costs (Figure 5a), the efficiency index (Figure 5c), and the number of replacements (Figure 5d) tend to decrease with the increase in the time interval between inspections, but service life tends to increase (Figure 5b).

\subsection{Analysis of the Best and Worst Solutions for Each Maintenance Strategy}

In order to compare the different optimal solutions for each maintenance strategy, radar charts [60] are used to display the four parameters (objective functions) in a bi-dimensional space and thus analyze the overall influence of each parameter. In Figure 6, for each maintenance strategy, only the three optimal solutions highlighted are plotted in the radar charts, but in the analyses to select the best and the worst solution, all solutions are considered. The optimal solutions highlighted are chosen from all optimal solutions obtained and represent the best, the worst, and an intermediate solution. In the radar charts, the solution with the largest area represents the most advantageous solution. The parameter values for each solution are presented in Table 4.

In Figure 6a, the optimal solutions highlighted for MS1 are compared. For this maintenance strategy, solution S2 reveals to be the best alternative. This solution presents a time interval between inspections of approximately 11 years and corresponds to a trade-off between the most economical solution (solution S1) and the most expensive one (solution S3). By comparing with solution S1, a slight increase in maintenance costs allows improving the aesthetical appearance and durability of the NSC. On the other hand, solution S3 identifies the least beneficial option for MS1. Although it has the highest efficiency index, the maintenance costs and the impact on users during the time horizon are higher. 
Finally, for this maintenance strategy, the time interval between inspections has a limited influence on the service life (approximately 70 years).

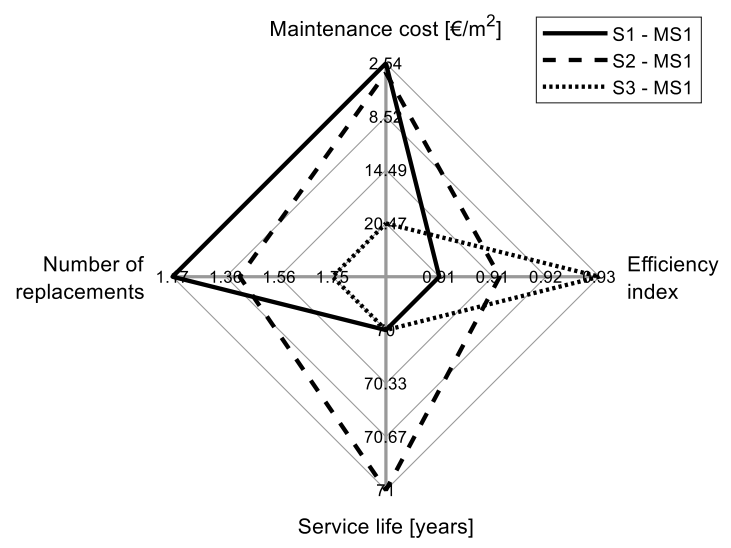

(a)

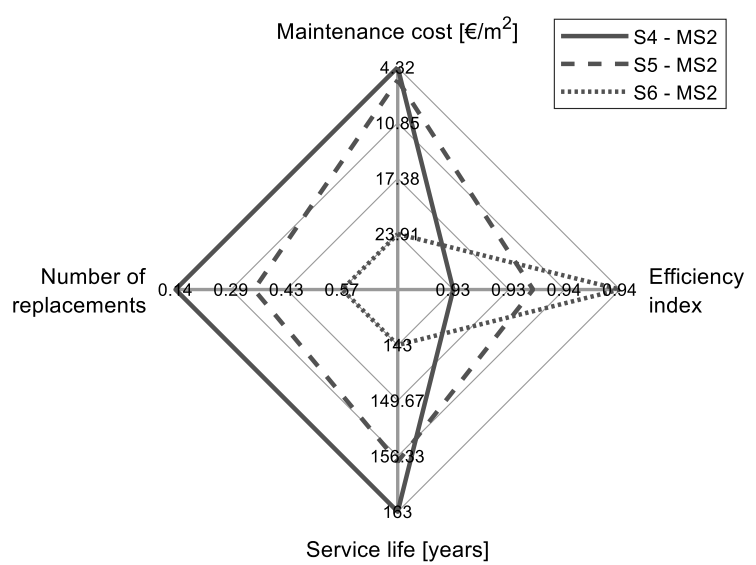

(b)

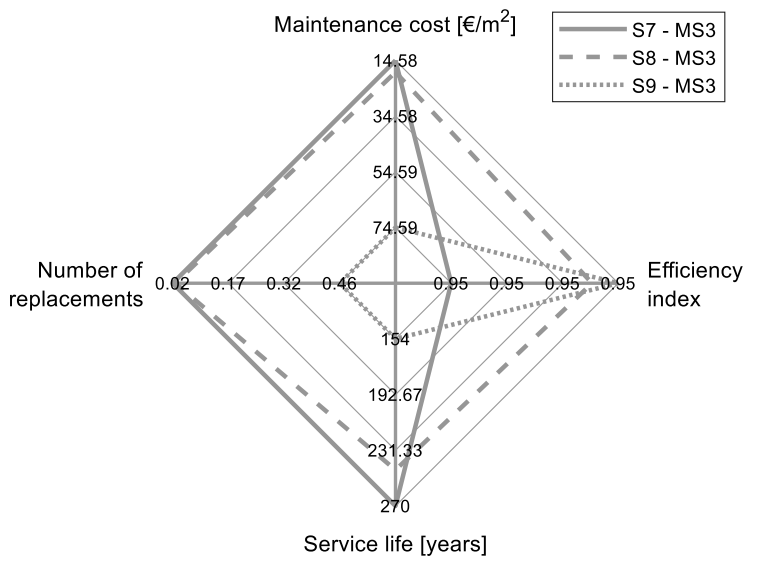

(c)

Figure 6. Comparison of the optimal solutions for: (a) maintenance strategy 1; (b) maintenance strategy 2; (c) maintenance strategy 3.

For MS2, the optimal solutions highlighted are shown in Figure $6 \mathrm{~b}$. The results reveal that the area for solution S4 is the largest among the three optimal solutions, indicating this solution as the most advantageous option for MS2. Solution S4 presents a time interval between inspections of approximately 19 years and, by slightly sacrificing the aesthetic appearance of the cladding, becomes the most economical solution with longer service life and a lower number of replacements during the time horizon. An inspection period of 19 years for NSC can be considered quite high for some owners/managers of buildings. Therefore, the solution S5, with an approximate time interval between inspections of 12 years, also represents a good alternative. Regarding the least advantageous alternative, this is identified by solution S6.

Finally, Figure 6c presents the optimal solutions highlighted for MS3. As for MS1, in this maintenance strategy, the results show that the trade-off solution (solution S8) identifies the best alternative, while the most expensive alternative (solution S9) is the least beneficial option. Solution S8 has an approximate time interval between inspections of 15 years, and, by comparing with the most economical solution (solution S7), with a reduction in the durability and slight increase of the maintenance costs, solution S8 maintains the number of replacements and allows improving the aesthetic appearance of the NSC. 


\subsection{Recommendation about the Most and the Least Advantageous Maintenance Strategy}

Finally, to select the more beneficial maintenance strategy to implement in NSC, in Figure 7a, the best optimal solutions of each maintenance strategy are compared. The results reveal that solution S2 (the best optimal solution from MS1) is the one with the lowest maintenance cost. However, as a trade-off, of the three maintenance strategies, solution S2 is the one that presents the greatest number of replacements during the time horizon of 150 years, the lowest efficiency index, and the shortest service life. On the other hand, solution S8 (best solution from MS3) represents the most expensive maintenance strategy, but this increase in the maintenance cost allows reducing the number of replacements and increasing the efficiency index and the service life when compared with the other maintenance strategies. Finally, solution S4 (best solution from MS2) is an interesting trade-off. When compared with solution S2, the slight increase in maintenance costs of solution S4 (approximately $20 \%$ ) allows significantly reducing the number of replacements during the time horizon and increasing the service life of the NSC and the efficiency index. In summary, the results obtained reveal that considering maintenance strategies with more maintenance activities is more efficient and has a higher impact on the improvement of NSC, promoting its durability. On the other hand, a more detailed intervention leads to higher maintenance costs. Regarding the worst maintenance strategies (Figure 7b), the results reveal that simpler maintenance strategies are less advantageous. Specifically, for the three maintenance strategies, solution S3 (worst solution from MS1) represents the least beneficial maintenance strategy to be implemented in NSC.

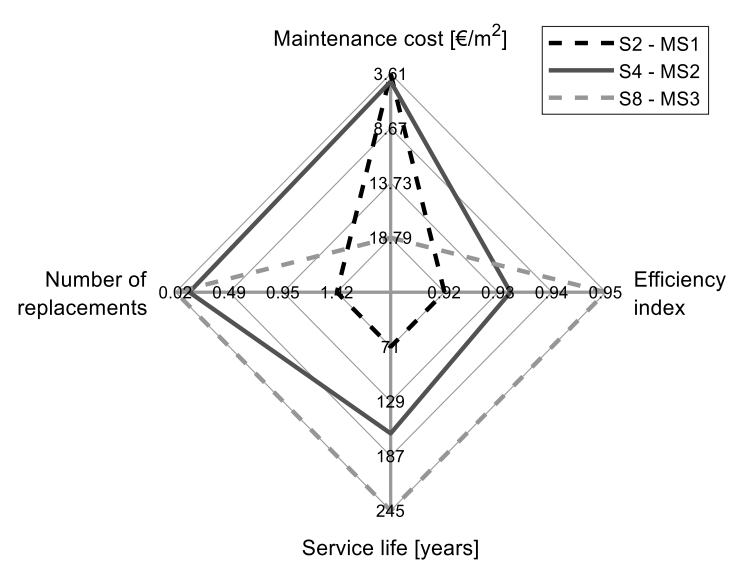

(a)

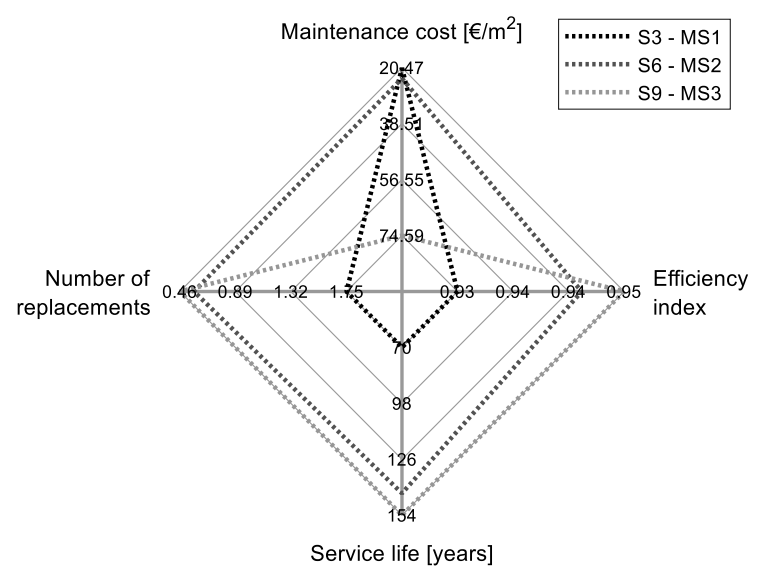

(b)

Figure 7. Comparison of the: (a) best optimal solutions of each maintenance strategy; (b) worst solutions of each maintenance strategy.

\section{Discussion}

The results obtained from the comparison of the optimal solutions for the different maintenance strategies (Figures 4 and 5), more specifically in Figure 4a,d and Figure 5b, may seem contradictory, but they are expected. The optimal solutions with the lowest maintenance costs are the ones with the highest time intervals between inspections, $t_{i n s p}$, as confirmed in Figure $5 \mathrm{a}$, which relates the design variable with the maintenance costs. If inspections are carried out more frequently (i.e., lower $t_{\text {insp }}$ ), then there is a greater likelihood of observing the end of the cladding's life earlier, and, consequently, the replacement of the NSC is performed earlier (decreasing the service life), and the number of replacements during the time horizon increases. In this study, it is assumed that the end of the service life is achieved when condition D of degradation is reached.

In addition, the decreased period of inspections also contributes to increasing the maintenance costs over time since it will increase the costs associated with the inspection activities. Table 5 shows that as the time interval between inspections decreases, the percentage of the costs associated with 
inspections increases significantly. For example, for MS1, by comparing with solution S1, the costs associated with the inspections for solution S2 increase by $123 \%$, and for solution S3, the value is approximately 33 times higher. On the other hand, the increase in the costs associated with the maintenance activities varies between $20 \%$ and $65 \%$. Similar conclusions can be observed for MS2 and MS3.

Table 5. Comparison of the costs associated with inspection and maintenance activities of the optimal solutions highlighted.

\begin{tabular}{|c|c|c|c|c|c|}
\hline $\begin{array}{l}\text { Maintenance } \\
\text { Strategy }\end{array}$ & $\begin{array}{l}\text { Optimal } \\
\text { Solution }\end{array}$ & $\begin{array}{c}\text { Time Interval, } \\
t_{i n s p} \text { (Years) }\end{array}$ & $\begin{array}{c}\text { Maintenance } \\
\text { Costs }\left(€ / \mathrm{m}^{2}\right)\end{array}$ & $\begin{array}{l}\text { Costs Associated with } \\
\text { Inspection }\left(\epsilon / \mathrm{m}^{2}\right)\end{array}$ & $\begin{array}{c}\text { Costs associated with } \\
\text { Maintenance }\left(€ / \mathrm{m}^{2}\right)\end{array}$ \\
\hline \multirow{3}{*}{ MS1 } & S1 & 18.8 & 2.54 & 0.52 & 2.02 \\
\hline & S2 & 10.9 & 3.61 & 1.16 & 2.45 \\
\hline & S3 & 1.0 & 20.47 & 17.16 & 3.31 \\
\hline \multirow{3}{*}{ MS2 } & S4 & 18.8 & 4.32 & 0.52 & 3.8 \\
\hline & S5 & 11.9 & 5.82 & 1.03 & 4.79 \\
\hline & S6 & 1.0 & 23.91 & 16.67 & 7.24 \\
\hline \multirow{3}{*}{ MS3 } & S7 & 19.0 & 14.58 & 0.51 & 14.07 \\
\hline & S8 & 15.4 & 18.79 & 0.71 & 18.08 \\
\hline & S9 & 1.0 & 74.59 & 17.16 & 57.43 \\
\hline
\end{tabular}

Other conclusions can be drawn from the direct comparison of the optimal solutions of the three maintenance strategies (Figure 4), which is that it is advantageous to implement strategies with more maintenance activities. For example, for similar maintenance costs, MS3 presents higher service lives, higher efficiency indexes, and a lower number of replacements. This observation is corroborated by the results provided in Figure 7. In Figure 7a,b, the best and the worst optimal solutions of each maintenance strategy are compared, respectively. The results reveal that by balancing the four objective functions, MS3 is the most advantageous maintenance strategy, while MS1 is the least advantageous maintenance strategy.

Additionally, from the analysis of the best and worst solutions for each maintenance strategy (Section 3.2), it can be concluded that the time intervals between inspections recommended in the literature are conservative. The literature review (Section 2.1.2) shows that the recommended inspection period to NSC ranges from 2 to 8 years. By comparing these results with the results of the most common value for inspections (5 years) [58], the results reveal that with a low impact on the aesthetic appearance (less than 2\%), a considerable reduction in the maintenance costs (ranging between $36 \%$ and $58 \%$ ) can be obtained by increasing the time interval between inspections. Furthermore, the results also reveal that when the period between inspections is increased, the assessment of the degradation condition of NSC is performed later in the cladding's life cycle, thus reducing the number of cleaning actions performed, also postponing the localized repairs. On the one hand, this has economic advantages, increasing the service life of the NSC (decreasing the number of total replacements and increasing the sustainability of NSC) and does not lead to significant differences in the claddings' condition. However, the values provided by the literature review (Section 2.1.2) are deterministic values, defined based on the experience of experts or suggested based on users' requirements. The main advantage of this study is the probabilistic framework of the methodology, which allows encompassing the uncertainty related to the inspection periods, proposing an optimization process to find the most adequate time intervals between inspections. In terms of constraints, as with other probabilistic methodologies, the main limitation of this methodology is the size and quality of the samples. If the sample in which the analysis is based is biased or with influential case studies, the results provided by the methodology will not be realistic.

Furthermore, it should be mentioned that the selection of the best maintenance strategy to implement in NSC is a dynamic task. The solution that is adequate for one owner or location/region may not show the same advantages in other places. These decisions are influenced by several factors, such as available budgets, degradation and performance levels, environmental exposure conditions, 
users' and owners' perceptions and requirements, local conditions to perform the maintenance works, and the economic and social context of the building, among others. These parameters will influence the degradation process and the impact of the maintenance strategies, and, consequently, different conclusions can be achieved. Therefore, this methodology allows building owners/managers to compare different alternatives and select one that shows a better compromise between the conflicting criteria. For example, let us assume the situation that the owner/manager has a maximum budget of $15.00 € / \mathrm{m}^{2}$ to perform the maintenance works during the time horizon of 150 years. By imposing this constraint, the results reveal that the best solution still belongs to MS3, but the time interval between inspections should be increased from 15 to 20 years (maintenance cost $=13.65 € / \mathrm{m}^{2}$; service life $=275$ years; efficiency index $=0.9466$; the number of replacements $=0.03$ ). In another situation, where the owner/manager does not want an inspection period higher than 10 years, the results show that the best solution is no longer from MS3 but rather MS2 and has a time interval between inspections of 9 years (maintenance cost $=6.87 € / \mathrm{m}^{2}$; service life $=155$ years; efficiency index $=0.9375$; the number of replacements $=0.38$ ).

Finally, multi-objective optimization is a tool, and the main aim of this study is to show its possibilities when applied to the schedule of inspections in maintenance plans. However, the decision-making behind the schedule of inspections is dependent on several factors. In this study, these four parameters (maintenance cost, service life, efficiency index, and the number of replacements) are chosen, but, depending on the decision maker's requests, other parameters can be evaluated.

\section{Conclusions}

In this study, a multi-objective optimization procedure is used to schedule inspection interventions on natural stone claddings. This work intends to understand whether there is an optimal time interval for performing the inspections, considering the several conflicts that the building owners/managers are subjected to. In this case study, the conflicting objectives considered are minimization of the service life cycle costs in terms of maintenance, maximization of the efficiency index of the maintenance plan, maximization of the service life, and minimization of the total number of replacements over the time horizon.

From the results, two main conclusions can be drawn. Firstly, it is advantageous to implement maintenance strategies with more maintenance activities (strategies that consider preventive interventions). For example, if the most advantageous maintenance strategies are compared, the consideration of maintenance strategies with more activities, although leading to higher maintenance costs, has a higher impact on the improvement of NSC, promoting its durability, protecting the environment, reducing the risks for society, and improving the aesthetic perception and comfort of the cities. Secondly, the time intervals between inspections recommended in the literature are conservative. In the literature, the recommended inspection period for NSC ranges from 2 to 8 years. This study shows that the inspection period can be increased to 11 to 15 years. The results reveal that a cost-saving of $36-58 \%$ can be achieved if the inspection period is increased, with a lower impact on the aesthetic appearance (less than $2 \%$ ).

Finally, it should be stressed that multi-objective optimization procedures are simply a tool to help decision-makers to make more rational and informed decisions. In the end, the selection of the best alternative is always performed by the building owners/managers and depends on their budgets, demands, and expectations. The main advantage of the multi-objective optimization procedures relies on the fact that it is not a closed methodology. As future research, this methodology can be used to analyze other maintenance strategies-in terms of the type of actions, the minimum requirements, or the environmental context, allowing considering different conflicting parameters-and applied to other buildings' constructive solutions or even the building as a whole. 
Author Contributions: Conceptualization, C.F.; methodology, C.F.; formal analysis, C.F.; investigation, C.F., A.S., J.d.B., I.S.D., I.F.-C.; writing-original draft preparation, C.F.; writing-review and editing, A.S., J.d.B., I.S.D., I.F.-C. All authors have read and agreed to the published version of the manuscript.

Funding: This research was funded by FCT (Portuguese Foundation for Science and Technology) through the project BestMaintenance-LowerRisks (PTDC/ECI-CON/29286/2017).

Acknowledgments: The authors gratefully acknowledge the support of the CERIS Research Institute, Instituto Superior Técnico, Universidade de Lisboa.

Conflicts of Interest: The authors declare no conflict of interest.

\section{References}

1. Sandak, A.; Sandak, J.; Brzezicki, M.; Riggio, M. Bio-Based Building Skin; Springer International Publishing: Singapore, 2019.

2. Khalid, E.I.; Abdullah, S.; Hanafi, M.H.; Said, S.Y.; Hasim, M.S. The consideration of building maintenance at design stage in public buildings: The current scenario in Malaysia. Facilities 2019, 37, 942-960. [CrossRef]

3. British Standards Institution. Code of Practice for the Design and Installation of Natural Stone Cladding and Lining_Part 1: General; Technical Report No. 8298-1; British Standards Institution (BSI): London, UK, 2010.

4. Haagenrud, S.E. Part II-Factors causing degradation. In Joint CIB W80/RILEM TC 140_Prediction of Service Life of Building Materials and Components_Guide and Bibliography to Service Life and Durability Research for Buildings and Components; Jernberg, P., Lacasse, M., Haagenrud, S., Sjöström, C., Eds.; Conseil International du Bâtiment: Rotterdam, The Netherlands, 2004; pp. 1-105.

5. Silva, A.; De Brito, J.; Gaspar, P.L. Methodologies for Service Life Prediction of Buildings: With a Focus on Façade Claddings; Springer International Publishing: Zurich, Switzerland, 2016.

6. Narayan, V. Effective Maintenance Management: Risk and Reliability Strategies for Optimizing Performance; Industrial Press Inc.: New York, NY, USA, 2004.

7. Faiz, R.B.; Edirisinghe, E.A. Decision making for predictive maintenance in asset information management. Interdiscip. J. Inf. Knowl. Manag. 2009, 4, 23-36. [CrossRef]

8. Kim, S.; Frangopol, D.M. Decision making for probabilistic fatigue inspection planning based on multi-objective optimization. Int. J. Fatigue 2018, 111, 356-368. [CrossRef]

9. Falorca, J.F. Main functions for building maintenance management: An outline application. Int. J. Build. Pathol. Adapt. 2019, 37, 490-509. [CrossRef]

10. Shohet, I.M.; Puterman, M.; Gilboa, E. Deterioration patterns of building cladding components for maintenance management. Constr. Manag. Econ. 2002, 20, 305-314. [CrossRef]

11. British Standards Institution. Facilities Maintenance Management. Code of Practice; Technical Report No. 8210; British Standards Institution (BSI): London, UK, 2020.

12. Bureau Veritas. Gestion Technique du Patrimoine—Réhabilitation et Maintenance, Guide Veritas du Bâtiment; Bureau Veritas: Paris, France, 1993.

13. Association Française de Normalisation. Maintenance. Concepts and Definitions of Maintenance Activities; Technical Report No. NF-X60-010; Association Française de Normalisation: Paris, France, 1994.

14. Emídio, F.; De Brito, J.; Gaspar, P.L.; Silva, A. Application of the factor method to the estimation of the service life of natural stone cladding. Constr. Build. Mater. 2014, 66, 484-493. [CrossRef]

15. Shohet, I.; Paciuk, M. Service life prediction of exterior cladding components under standard conditions. Constr. Manag. Econ. 2004, 22, 1081-1090. [CrossRef]

16. Agence Qualité Construction. Fiches Pathologie Bâtiment; Agence Qualité Construction: Paris, France, 2019.

17. Building Research Establishment. Defect Action Sheets-The Complete Set; Building Research Establishment Press: London, UK, 2001.

18. Chang, C.Y.; Tsai, M.D. Knowledge-based navigation system for building health diagnosis. Adv. Eng. Inf. 2013, 27, 246-260. [CrossRef]

19. Chew, Y.L. Maintainability of Facilities: For Building Professionals; Worlds Scientific Publishing Co. Pte. Ltd.: Singapore, 2010.

20. Conseil International du Bâtiment. Building Pathology: A State-of-the-Art Report; Technical Report No. W86; Conseil International du Bâtiment: Delft, The Netherlands, 1993. 
21. Lacasse, M.A.; Kyle, B.; Talon, A.; Boissier, D.; Hilly, T.; Abdulghani, K. Optimization of the building maintenance management process using a Markovian model. In Proceedings of the 11DBMC International Conference on Durability of Building Materials and Components, Istanbul, Turkey, 11-14 May 2008.

22. Lind, H.; Muyingo, H. Building maintenance strategies: Planning under uncertainty. Prop. Manag. 2012, 30, 14-28. [CrossRef]

23. Madureira, S.; Flores-Colen, I.; De Brito, J.; Pereira, C. Maintenance planning of facades in current buildings. Construct. Build. Mater. 2017, 147, 790-802. [CrossRef]

24. Ruparathna, R.; Hewage, K.; Sadiq, R. Multi-period maintenance planning for public buildings: A risk based approach for climate conscious operation. J. Clean. Prod. 2018, 170, 1338-1353. [CrossRef]

25. Dekker, R. Applications of maintenance optimization models: A review and analysis. Reliab. Eng. Syst. Saf. 1996, 51, 229-240. [CrossRef]

26. MatLab. Available online: https://www.mathworks.com/help/gads/gamultiobj.html (accessed on 15 September 2020).

27. Liu, M.; Frangopol, D.M. Optimizing bridge network maintenance management under uncertainty with conflicting criteria: Life-cycle maintenance, failure, and user costs. J. Struct Eng. 2006, 132, 1835-1845. [CrossRef]

28. Bocchini, P.; Frangopol, D.M. A probabilistic computational framework for bridge network optimal maintenance scheduling. Reliab. Eng. Syst. Saf. 2011, 96, 332-349. [CrossRef]

29. Orcesi, A.D.; Cremona, C.F. A bridge network maintenance framework for Pareto optimization of stakeholders/users costs. Reliab. Eng. Syst. Saf. 2010, 95, 1230-1243. [CrossRef]

30. Orcesi, A.D.; Cremona, C.F. Optimal maintenance strategies for bridge networks using the supply and demand approach. Struct. Infrastruct. Eng. 2011, 7, 765-781. [CrossRef]

31. Dandy, G.C.; Engelhardt, M. Optimal scheduling of water pipe replacement using genetic algorithms. J. Water Resour. Plan. Manag. 2001, 127, 214-223. [CrossRef]

32. Alvisi, S.; Franchini, M. Multiobjective optimization of rehabilitation and leakage detection scheduling in water distribution systems. J. Water Resour. Plan. Manag. 2009, 135, 426-439. [CrossRef]

33. Castro, P.M.; Grossmann, I.E.; Veldhuizen, P.; Espin, D. Optimal maintenance scheduling of a gas engine power plant using generalized disjunctive programming. AIChE J. 2014, 60, 2083-2097. [CrossRef]

34. Bianchini, A.; Pellegrini, M.; Rossi, J. Maintenance scheduling optimization for industrial centrifugal pumps. Int. J. Syst. Assur. Eng. Manag. 2019, 10, 848-860. [CrossRef]

35. Hegazy, T.; Elhakeem, A. Multiple optimization and segmentation technique (MOST) for large-scale bilevel life cycle optimization. Can. J. Civ. Eng. 2011, 38, 263-271. [CrossRef]

36. Dao, C.; Basten, R.; Hartmann, A. Maintenance scheduling for railway tracks under limited possession time. J. Transp. Eng. Part A Syst. 2018, 144. [CrossRef]

37. Hopland, A.O.; Kvamsdal, S.F. Optimal maintenance scheduling for local public purpose buildings. Prop. Manag. 2016, 34, 120-135. [CrossRef]

38. Berardi, L.; Giustolisi, O.; Savic, D.A.; Kapelan, Z. An effective multi-objective approach to prioritisation of sewer pipe inspection. Water Sci. Technol. 2009, 60, 841-850. [CrossRef]

39. Elmasry, M.; Zayed, T.; Hawari, A. Multi-objective optimization model for inspection scheduling of sewer pipelines. J. Constr. Eng. Manag. 2019, 145. [CrossRef]

40. Zio, E.; Viadana, G. Optimization of the inspection intervals of a safety system in a nuclear power plant by multi-objective differential evolution (MODE). Reliab. Eng. Syst. Safe 2011, 96, 1552-1563. [CrossRef]

41. International Organization for Standardization. Buildings and Constructed Assets-Service Life Planning-Part 1: General Principles and Framework; Technical Report No. 15686-1; International Organization for Standardization: Geneva, Switzerland, 2011.

42. Farahani, A.; Wallbaum, H.; Dalenbäck, J.O. Optimized maintenance and renovation scheduling in multifamily buildings-A systematic approach based on condition state and life cycle cost of building components. Constr. Manag. Econ. 2019, 37, 139-155. [CrossRef]

43. Grelk, B.; Christiansen, C.; Schouenborg, B.; Malaga, K. Durability of marble cladding-A comprehensive literature review. J. ASTM Int. 2007, 4, 1-19. [CrossRef]

44. Farmer, M.C.; Lyons, S.P. Stone cladding failure: The cause and consequences. In Proceedings of the 2 nd Forensic Engineering Congress, San Juan, Puerto Rico, 21-23 May 2000.

45. Thai-Ker, L.; Chung-Wan, W. Challenges of external wall tiling in Singapore. In Proceedings of the Qualicer 2006: IX World Congress on Ceramic Tile Quality, Castellón, Spain, 12-15 February 2006. 
46. Loughran, P. Failed Stone: Problems and Solutions with Concrete and Masonry; Birkhäuser-Publishers for Architecture: Basel, Switzerland, 2007.

47. Siegesmund, S.; Snethlage, R. Stone in Architecture Properties, Durability; Springer: Berlin/Heidelberg, Germany, 2014.

48. Gaspar, P.; De Brito, J. Service life estimation of cement-rendered facades. Build. Res. Inf. 2008, 36, 44-55. [CrossRef]

49. Silva, A.; De Brito, J.; Gaspar, P.L. Service life prediction model applied to natural stone wall claddings (directly adhered to the substrate). Constr. Build. Mater. 2011, 25, 3674-3684. [CrossRef]

50. Branco, F.A.; De Brito, J. Handbook of Concrete Bridge Management; ASCE Press: Reston, VA, USA, 2004.

51. Decree-Law No. 177/2001 (in Portuguese). Available online: https://dre.pt/pesquisa/-/search/331257/details/ maximized (accessed on 8 October 2020).

52. Wildman, R.; Gaynor, A. Topology optimization for robotics applications. In Robotic Systems and Autonomous Platforms, 1st ed.; Walsh, S.M., Strano, M.S., Eds.; Woodhead Publishing in Materials: Cambridge, UK, 2019; pp. 251-292.

53. Deb, K. Introduction to evolutionary multiobjective optimization. In Multiobjective Optimization: Interactive and Evolutionary Approaches, 1st ed.; Branke, J., Deb, K., Miettinen, K., Słowiński, R., Eds.; Springer: Berlin/Heidelberg, Germany, 2008; pp. 59-96.

54. Ferreira, C.; Neves, L.C.; Silva, A.; De Brito, J. Stochastic maintenance models for ceramic claddings. Struct. Infrastruct. Eng. 2020, 16, 247-265. [CrossRef]

55. Sánchez-Silva, M.; Klutke, G.-A. Reliability and Life-Cycle Analysis of Deteriorating Systems; Springer International Publishing: Zurich, Switzerland, 2016.

56. Frangopol, D.M.; Kallen, M.J.; Van Noortwijk, J.M. Probabilistic models for lifecycle performance of deteriorating structures: Review and future directions. Prog. Struct. Eng. Mater. 2004, 6, 197-212. [CrossRef]

57. Langdon, D. Life Cycle Costing (LCC) as a Contribution to Sustainable Construction. Guidance on the Use of the LCC Methodology and Its Application in Public Procurement; Davis Langdon Management Consulting: London, UK, 2007.

58. Ferreira, C.; Silva, A.; De Brito, J.; Dias, I.S.; Flores-Colen, I. Definition of a condition-based model for natural stone claddings. J. Build. Eng. 2020, 33, 101643. [CrossRef]

59. Kalbfleisch, J.D.; Lawless, J.F. The analysis of panel data under a Markov assumption. J. Am. Stat. Assoc. 1985, 80, 863-871. [CrossRef]

60. Spider_plot. Available online: https://github.com/NewGuy012/spider_plot (accessed on 25 August 2020).

Publisher's Note: MDPI stays neutral with regard to jurisdictional claims in published maps and institutional affiliations.

(C) 2020 by the authors. Licensee MDPI, Basel, Switzerland. This article is an open access article distributed under the terms and conditions of the Creative Commons Attribution (CC BY) license (http://creativecommons.org/licenses/by/4.0/). 